\title{
Numerical investigations of multicomponent process lightweight design for joining gearwheels by lateral extrusion
}

\author{
Robert Meissner $^{1, a}$ and Mathias Liewald ${ }^{1}$ \\ ${ }^{1}$ Institute for Metal Forming Technology, University of Stuttgart, Germany
}

\begin{abstract}
Multicomponent processes for production of high performance gearwheels combines both high power density and high lightweight potential. In this paper, the focus is on manufacturing an assembled gearwheel using cold forging and simultaneously joining the gearwheel body and a gear ring. In this study, FEA results regarding the joining process of two different materials for assembled gearwheels are presented. The aim of the numerical investigation is to achieve a robust forging process and define appropriate tool parameters.
\end{abstract}

\section{Introduction}

Funded by the Federal Ministry of Economic Affairs and Energy BMWi via the German Industrial Federation of Industrial Research Associations AiF, the joint research project "massiver Leichtbau" started in May 2015. In the context of this project, lightweight potentials of forged components are investigated in five work packages using different methods. In order to identify and to make use of lightweight potential of forged parts, networking of several stages of production becomes essential. The work package ,Intelligent lightweight design through multicomponent processes", run by the Gear Research Centre (FZG) of the Technical University of Munich, investigates the potential of using assembled gearwheels. A common gearwheel is divided into three parts - gear ring, gearwheel body, and shaft - and the substitution of the gearwheel body will be investigated using different manufacturing processes. In the investigations, special heat treated gear rings provided by the Institute of Material Science in Bremen (IWT) will be used. The Institute of Metal Forming and Casting (Utg Munich) of the Technical University of Munich deals with a gearwheel body made of joint sheet metal and deep drawn gearwheel body. The assembled gearwheel will be manufactured at the Institute for Metal Forming Technology (IFU Stuttgart) of the University of Stuttgart by forging the gearwheel body into the gear ring.

The forging process of an assembled gearwheel will be performed by laterally extruding a blank, placed between shaft and gear ring. Therefore, numerical simulations are necessary to define the process limits and design the forging tools. Joining by forming can be performed in various ways. Former investigations focused on forming a shaft into a hub, for example by internal high pressure forming or by using a heated hub and a cold shaft. [1,2] Dörr and Funk examined joining by forming processes by laterally extruding a shaft into a hub. [3] Funk used several inner hub geometries such as polygons (P3G) as well as simple and complex cycloids. Regarding the punch force, the roundness deviation of the hub and the torque transmission a profile with six extensions leads to the best result. [4,5] According to Funk, epitrochoids are most promising concerning process requirements during the forging process and while used. [6] Hence, in order to achieve a force-fit and form-fit joint of the gear ring and the gearwheel body, several inner gear ring geometries must be investigated.

The design of the inner geometry of the gear ring will adapt to these results. Due to a higher axial work load, in case of the built gearwheel coming from a helical gearing, an additional axial form-fit will be generated by creating a cavity on the inside of the gear ring. Next, the investigations in this paper will show how the inner geometry affects material flow and work load during the forging process to predict a promising geometry for experimental tests. In order to design the tools for experimental investigations, the work load was determined considering maximum lightweight potential of the gearwheel body. Further investigations were conducted regarding tribology behaviour and elastic behaviour of the gear ring during the process and after the process respectively.

\section{Numerical model setup}

The fundamental tool concept is shown in Figure 1. Experiments will be performed on a one-stage hydraulic press. In order to initiate lateral extrusion material flow, a closing device will be used. The synchronization of the upper and lower closing device is achieved by adjusting the closing force of both acting against each other. In [7], it is shown that the synchronization has significant

\footnotetext{
a Corresponding author: robert.meissner@ifu.uni-stuttgart.de
} 
influence on part quality regarding axial symmetry of forged parts produced by lateral extrusion. Therefore, a hydraulic closing device must adjust the upper and lower closing forces precisely. Using hydraulic chambers, nitrogen storages are mounted on each hydraulic chamber and separated by a membrane. The nitrogen storages themselves cause an increase of pressure in the hydraulic chamber. Therefore, the synchronization is performed by adjusting the upper and lower pressure in the nitrogen storages.
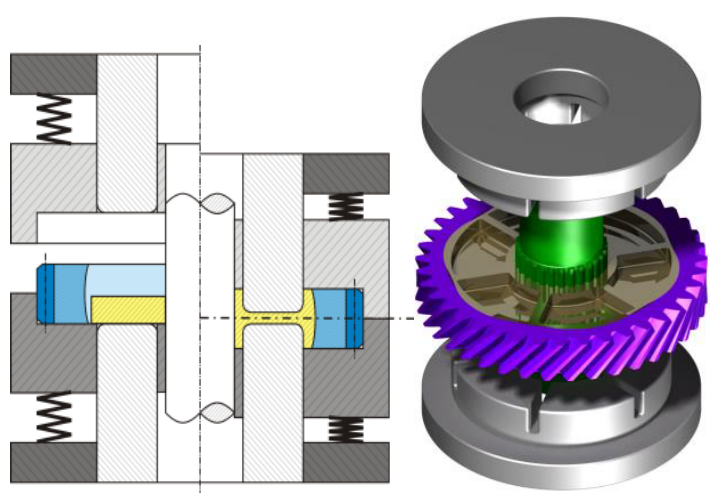

Figure 1: Tool concept for lateral extrusion (left) and built gearwheels (right)

In order to determine process properties and design the tool concept, only tools directly touching the part during the forging process were considered. The investigation was divided into two parts. First, the effect of geometrical modifications on material flow and work load was examined. In the next stage, elastic behaviour of the gear ring during and after the process was investigated. With regard to all process simulation runs, the parameters in table 1 were considered and kept constant.

Table 1. Geometrical conditions

\begin{tabular}{|c|c|}
\hline Part & Dimension \\
\hline Diameter of inner gear ring $\mathrm{D}_{\mathrm{Zi}}$ & $77 \mathrm{~mm}$ \\
\hline Diameter of outer gear ring $\mathrm{D}_{\mathrm{Zo}}$ & $94.12 \mathrm{~mm}$ \\
\hline Diameter of shaft $\mathrm{D}_{\mathrm{W}}$ & $30 \mathrm{~mm}$ \\
\hline
\end{tabular}

During the forging process, a constant punch velocity of $100 \mathrm{~mm} / \mathrm{s}$ was used. In order to save computing time, the smallest geometry model was used considering axial and rotational symmetries.

\section{MATERIAL DATA}

The investigations were conducted using steel C15. In order to determine the lightweight potential, steel was replaced with material $\mathrm{Al} 1070 \mathrm{~A}$ and was used for the comparison. The material properties are shown in table 2 . Flow curves were obtained up to a deformation degree of 0.8 by conducting compression tests. For calculating higher deformation degrees, flow stress was extrapolated linearly.
Table 2. Material parameters for simulation

\begin{tabular}{|c|c|c|c|}
\hline Properties & Unit & C15 & Al 1070A \\
\hline E-Module & {$\left[\mathrm{N} / \mathrm{mm}^{2}\right]$} & 210,000 & 68,900 \\
\hline Tensile Strength & {$\left[\mathrm{N} / \mathrm{mm}^{2}\right]$} & 360 & 57 \\
\hline Poisson Ratio & {$[-]$} & 0.3 & 0.33 \\
\hline Density & {$\left[\mathrm{g} / \mathrm{cm}^{3}\right]$} & 7.87 & 2.70 \\
\hline
\end{tabular}

\subsection{Investigations on material flow and tool load}

The joining of a gearwheel body by lateral extrusion is an axial symmetric process. Therefore, only the upper tools were investigated regarding material flow and tool work load. Punch, shaft, and gear ring were considered rigid, while the workpiece was modelled as a plastic model with a mesh of 80.000 elements. DEFORM $3 \mathrm{D}^{\mathrm{TM}}$ was used for the simulation.

\subsubsection{Standard geometry}

In order to investigate material flow and punch work load in particular, the geometrical parameters "outer diameter of blank to blank height ratio", "extensions of inner gear ring profile", "punch segmentation", "wall thickness", "eccentricity", "cavity", "ratio profile extensions to punch segmentation", "positioning of profile extensions to punch segmentation" and "positioning of upper punch to lower punch" were varied.

At the beginning, a basic value was determined. In order to investigate the effects of each parameter, only one parameter was varied regarding size. In table 3 , the basic parameters are listed with the corresponding standard values.

Table 3. Standard parameter values

\begin{tabular}{|c|c|}
\hline Parameter & dimension \\
\hline $\begin{array}{c}\text { Outer diameter of blank to blank } \\
\text { height ratio }\end{array}$ & 8.1 \\
\hline Friction & 0.12 \\
\hline $\begin{array}{c}\text { Extensions in inner gear ring } \\
\text { profile }\end{array}$ & 6 \\
\hline Punch segmentation & $3 \mathrm{~mm}$ \\
\hline Wall thickness & $1.4 \mathrm{~mm}$ \\
\hline Eccentricity & $0.7 \mathrm{~mm}$ \\
\hline Cavity depth & 1 \\
\hline $\begin{array}{c}\text { Ratio profile extensions to } \\
\text { punch segmentation }\end{array}$ & Parallel \\
\hline $\begin{array}{c}\text { Positioning of profile extensions } \\
\text { to punch segmentation }\end{array}$ & $\begin{array}{c}\text { punch spacing between } \\
\text { two extensions }\end{array}$ \\
\hline $\begin{array}{c}\text { Positioning of upper punch to } \\
\text { lower punch }\end{array}$ & \\
\hline
\end{tabular}




\subsubsection{Layout of blank geometry}

The inner diameter of the blanks was kept constant at $30 \mathrm{~mm}$. In order to direct material flow on the inner (shaft side) and on the outer side (gear ring side), outer diameter to blank height ratios were investigated to achieve a constant part height after forging several blanks. The maximum outer diameter of the blank was $74.5 \mathrm{~mm}$ being the smallest considered inner diameter of the gear ring. Seven different outer diameters were investigated starting at $74.5 \mathrm{~mm}$ and decreased about $1 \mathrm{~mm}$.

\subsubsection{Design of punch segmentation}

The punch segmentation causes different shapes of gearwheel bodies, and therefore, a different number of bridges affecting the mechanical behaviour are produced. A punch having four to nine segments was investigated, shown in figure 2. A conventional flow shoulder, as used in forward extrusion processes, was not considered for usage since the effective contacting length of the punch and the blank was $4 \mathrm{~mm}$ at a maximum. The distance between two segments was kept constant at each point of the segments.

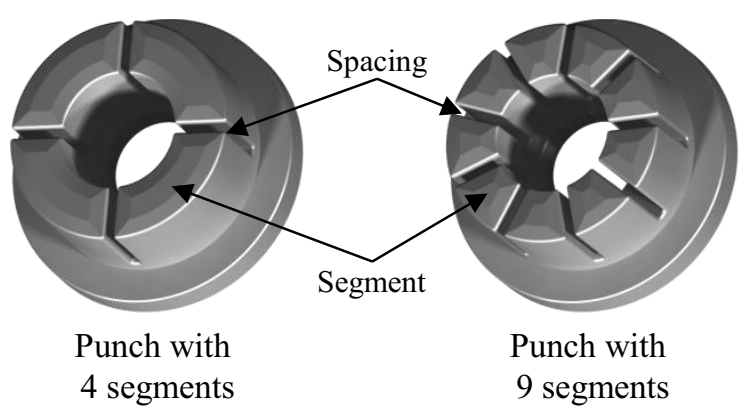

Figure 2: Design of punch segments

The variation of the wall thickness of the gearwheel body was performed by adjusting the distance between two segments of a punch as well as the distance between punch and gear ring and between punch and shaft. The thickness of the gear wheel bottom was adjusted to the other thicknesses. Wall thicknesses of $2 \mathrm{~mm}, 3 \mathrm{~mm}$, and $4 \mathrm{~mm}$ were investigated. The wall thickness was kept constant at each part of the gearwheel body.

\subsubsection{Profile of inner gear ring}

Dörr conducted numerous investigations on the geometrical design of inner hub profiles by joining a shaft with a hub using lateral extrusion. [4,5] He showed that an epitrochoid profile with six extensions results in high form filling and sufficient work load of the hub. Based on these investigations, epitrochoid profiles were used for the inner gear ring geometry in the presented investigations. The profile contour is expressed by equation (1).

$$
\begin{aligned}
& x=(R+r) \cdot \cos (\alpha)-a \cdot \cos \left(\left(1+\frac{R}{r}\right) \cdot \alpha\right) \\
& y=(R+r) \cdot \sin (\alpha)-a \cdot \sin \left(\left(1+\frac{R}{r}\right) \cdot \alpha\right)
\end{aligned}
$$

An epitrochoid is created by tracing a point $P$ attached to a circle of a radius $r$ rolling around the outside of a fixed circle of radius $R$. The measure of this point is indicated as a multiple of the rolling circle radius. [8] Following the definitions were made: parameter $a$ has to be radian measure and was set to $0.7 \mathrm{~mm}$. The inner circle radius $R$ is fixed to a radius of $37.1 \mathrm{~mm}$. The diameter of the epitrochoid outer envelope was kept constant at $77 \mathrm{~mm}$ in order to maintain a gear ring thickness comparable to the other investigations in this project. The profiles in figure 3 have as many profile extensions as punch segmentations (4-9S), while the inner and outer envelope remain constant.

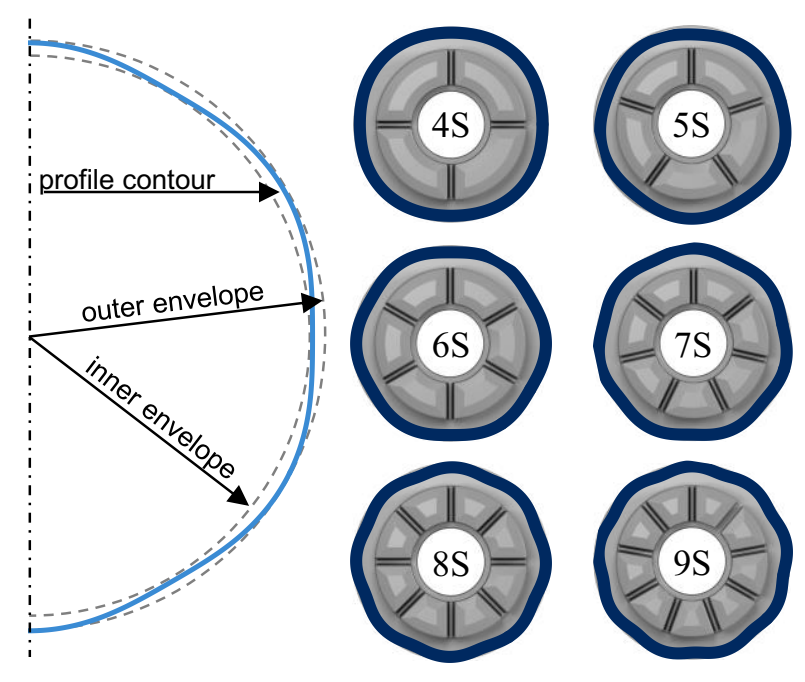

Figure 3: Various punch segmentations having four (4S) to nine (9S) segments with corresponding epitrochoid profiles

In order to increase a force fit during usage and to determine the effect on punch force and material flow, the eccentricity of the inner and outer envelopes, shown in figure 3, was varied by altering parameter $R$ and $a$ in the epitrochoid equation (1). These alterations change the distance between inner and outer envelope. The eccentricities $0.7 \mathrm{~mm}, 1.4 \mathrm{~mm}$, and $2.0 \mathrm{~mm}$ were investigated.

In order to investigate the cavity at the inner gear ring, a fixed inner diameter had to be determined first. Secondly, the cavity cannot exceed a diameter of $77.0 \mathrm{~mm}$, since the stability of the gear ring would be affected significantly. Therefore, the cavity was referenced to a fixed diameter of $74.2 \mathrm{~mm}$ and enters the gear ring up to $1.4 \mathrm{~mm}$ as shown in figure 4 . Five cavities were investigated having a maximum distance to inner diameter of $0.0 \mathrm{~mm}, 0.3 \mathrm{~mm}, 0.7 \mathrm{~mm}$ and $1.4 \mathrm{~mm}$. 


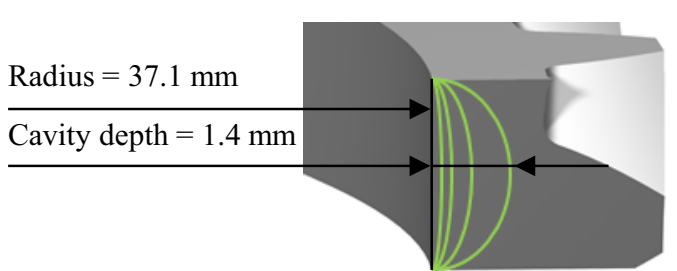

Figure 4: Cavity depth to be filled at the inner side of the gear ring

\subsubsection{Positioning of upper punch to lower punch and punch to gear ring}

In three different positions, the influence of punch positions to each other as well as the positioning of punch segments to the gear ring was investigated with regard to material flow, see figure 5. Firstly, both upper punch and lower punch were positioned parallel and the extensions of the gear ring were placed in the middle of a punch segment. Afterwards, the lower punch was turned by half the angle of a segment. Finally, the gear ring was turned by half the angle of a segment: more explicitly, the profiles' extensions were placed between two punch segments.

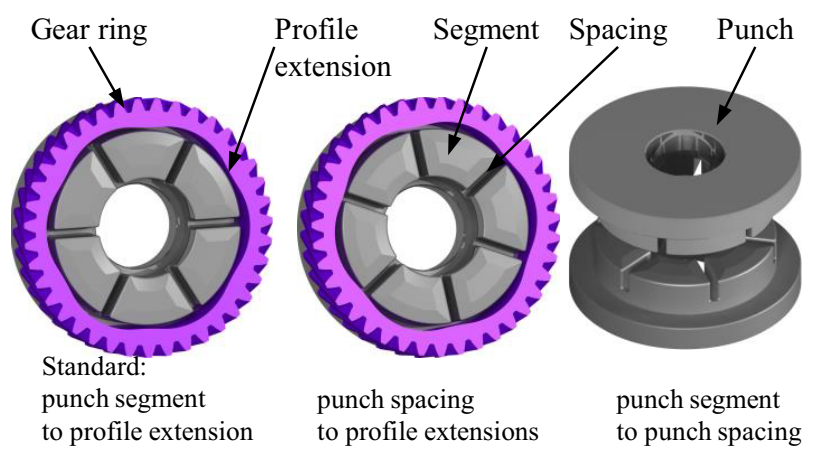

Figure 5: Tool and gear ring alignments to be investigated

\subsubsection{Filling of shaft gearing}

In order to manufacture a completely assembled gearwheel, a final investigation of joining by forming of a gearwheel body with a gear ring and a shaft was conducted. Therefore, geometrical data of the shaft having a toothing was provided by FZG. The material flow was investigated by altering the inner punch diameter regarding a wall thickness of $3 \mathrm{~mm}$. Next, the related diameter of the shaft was referenced to the tooth root diameter, the pitch circle, and tip diameter.

\subsection{Elastic behaviour and stress distribution}

During the forging process, radial compression stresses are applied on the gear ring, resulting in tangential tensile stresses on the outside. In order to prevent cracks, elastic numerical simulations were carried out. These investigations were performed to predict both radial deformations and stresses, and to make a point for a tool concept to implement a system for application of a radial preload. Furthermore, the elastic behaviour after ejection of the part was investigated to analyse the remaining pressure between the gearwheel body and the gear ring. Two setups were prepared for the investigation. First, the gear ring was fixed by its symmetric boundary conditions, but was free to expand to the outside. For the second setup, a rigidly modelled die was placed on the outside of the gear ring to simulate a fix bearing during the forging process.

\section{Results and discussion}

\subsection{Material flow and tool load}

\subsubsection{Influence of material on punch force}

In figure 6, the punch force versus punch stroke diagram is shown for two materials regarding the basic parameter setup. Up to a punch stroke of $0.8 \mathrm{~mm}$, a rather linear punch force increase can be detected. At this point the blank touches the gear ring, which results in a higher punch force, and therefore, increases to a punch stroke of $1.2 \mathrm{~mm}$. Next, the punch force increases slightly to a punch stroke of $2.6 \mathrm{~mm}$. The slight increase of punch force is caused by a growing friction surface on the punch, shaft, and gear ring. Using aluminium Al 1070A to forge the gearwheel body, it was determined that the maximum punch force was $82 \%$ lower in comparison to steel C15. In order to evaluate the influence of friction on punch forces, three cold forging friction values were investigated regarding material $\mathrm{C} 15$. At the beginning of the process, the influence of friction cannot be detected. The influence of friction increases at a punch stroke of approx. $1.3 \mathrm{~mm}$ when the contacting surface of the inner gear ring increases. Thus, friction forces increase as well, but only have a minor effect on the maximum punch force.

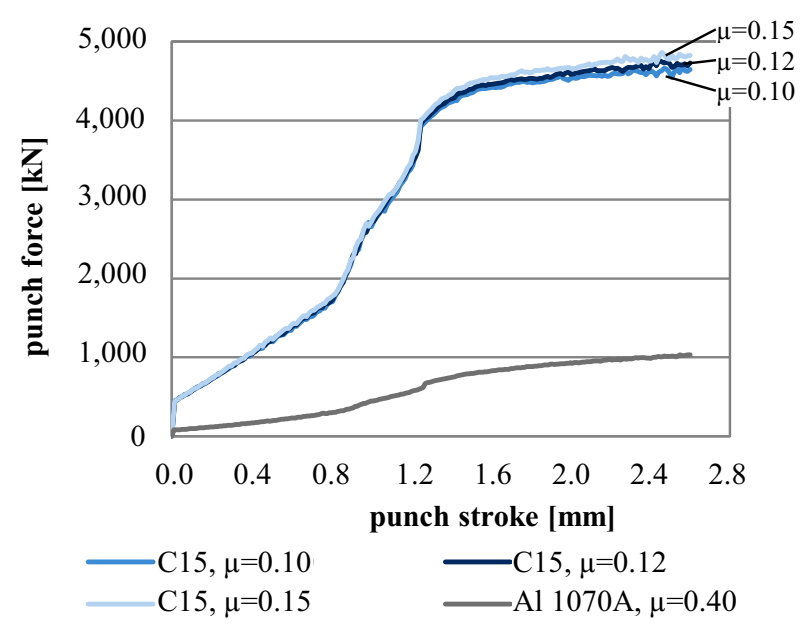

Figure 6: Punch force to punch stroke curve for steel C15, aluminium $\mathrm{Al} 1070 \mathrm{~A}$ and different friction values

\subsubsection{Influence of blank geometry layout on part height}

The influence of the layout of blank geometry is shown in figure 7. Four measurements were taken on the outer edges of the investigated symmetric part and one to 
determine the bridge height in order to calculate the average height of a part.

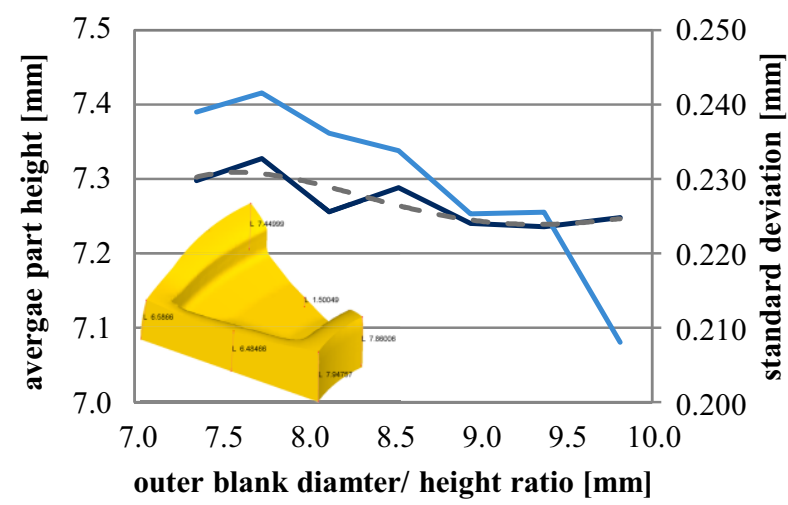

- average height standard deviation

Figure 7: Average part height and standard deviation for different initial outer blank diameter to height ratios

The average value, as well as the standard deviation, is depicted on the ordinate for an increasing outer blank diameter to height ratio on the abscissa. Therefore, it can be concluded that a higher outer blank diameter results in a more balanced part height. A trendline representing a polynom grade four shows a minimum at a ratio of 9.5 in figure 7. The outer blank diameter to height ratio is limited since the maximum outer blank diameter has to be smaller than $75 \mathrm{~mm}$ in order to be able to place the sample in the gear ring before starting the forging process.

\subsubsection{Design of punch segmentation}

In order to investigate the influence of various punch segmentations (figure 3) on punch forces, both punch segment and gear ring profiles were varied to have the same segments and extensions respectively. In figure 7, punch force to punch stroke diagram is depicted for segments varying from four (4S) to nine (9S).

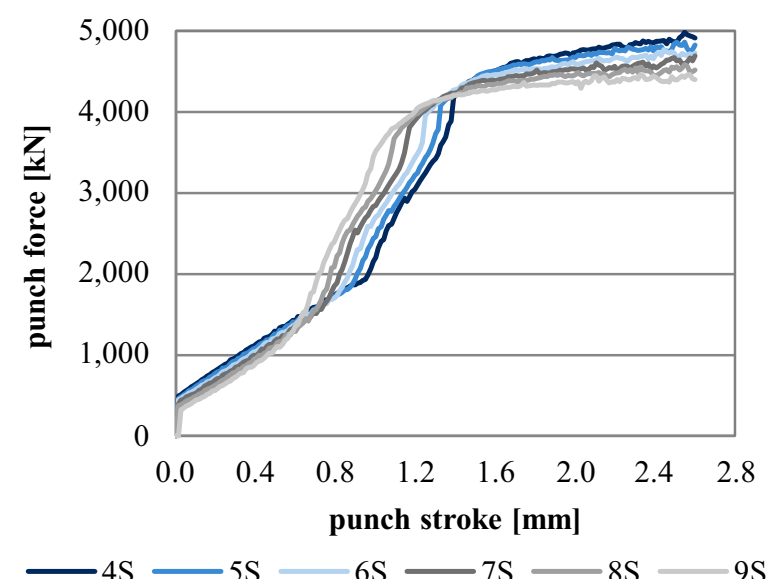

Figure 8: Punch forces for different punch segmentations
It can be concluded that fewer segments cause higher maximum punch forces, but on the other hand, the punch force increases at a later point during the process. In order to evaluate the occurring loads, the punch compression stresses have to be taken into account. In doing so, a small incline of the punch stress for numerical setup with more punch segments was detected.

In figure 9 a bar chart displays maximum compression stresses of different punch designs having four (4S) to nine (9S) segments. The punch stresses increase with a higher number of segments. However, this increase remains below $1 \%$ when comparing two punches with four and nine segments respectively. As opposed to this, weight reduction potential decreases from $54 \%$ to $49 \%$ in reference to a conventional gearwheel body.

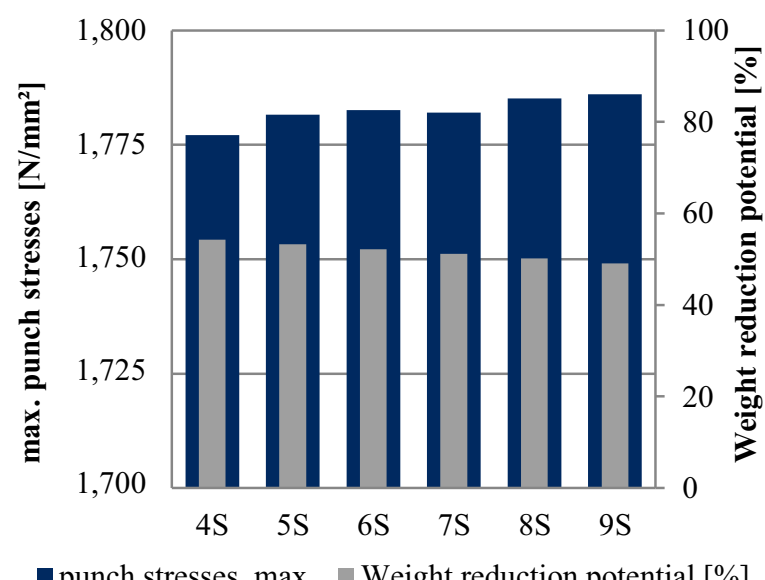

Figure 9: Maximum punch stresses and gearwheel body lightweight potentials related to full gearwheel bodies

Varying the wall thickness (distances between punch to gear ring, punch segment to punch segment and punch to shaft) causes a significant change of maximum punch force as can be seen in figure 10. Decreasing the wall thickness to $2 \mathrm{~mm}$ results in an increase of maximum punch force of $30,4 \%(+1.421 \mathrm{kN})$ and an increase of punch stress of $15.0 \%\left(+313.9 \mathrm{~N} / \mathrm{mm}^{2}\right)$. However, lightweight potential of the gearwheel body could reach $66 \%$.

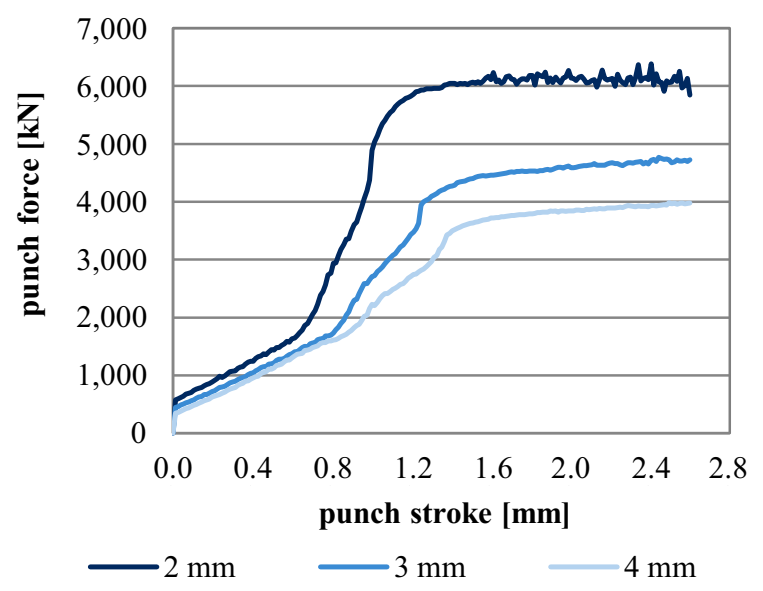

Figure 10: Calculated punch forces for different wall thicknesses of the gearwheel body 
On the contrary, the lightweight potential of the gearwheel body decreases to $40 \%$ when increasing the wall thickness to $4 \mathrm{~mm}$. Therefore, the maximum punch force decreases by $16.2 \%(-757 \mathrm{kN})$ and the maximum punch compression stresses decrease by $0.1 \%\left(-0.9 \mathrm{~N} / \mathrm{mm}^{2}\right)$. This small decrease results from a smaller cross sectional area of the punch.

\subsubsection{Alteration of profile of inner gear ring}

In order to investigate the influence of the inner gear ring profile on punch forces, the profile's eccentricity and cavity were varied. In figure 11, the punch force to punch stroke course is displayed for different eccentricities (parameter e) as well as different cavity depths (parameter c), representing the inner gear ring profile.

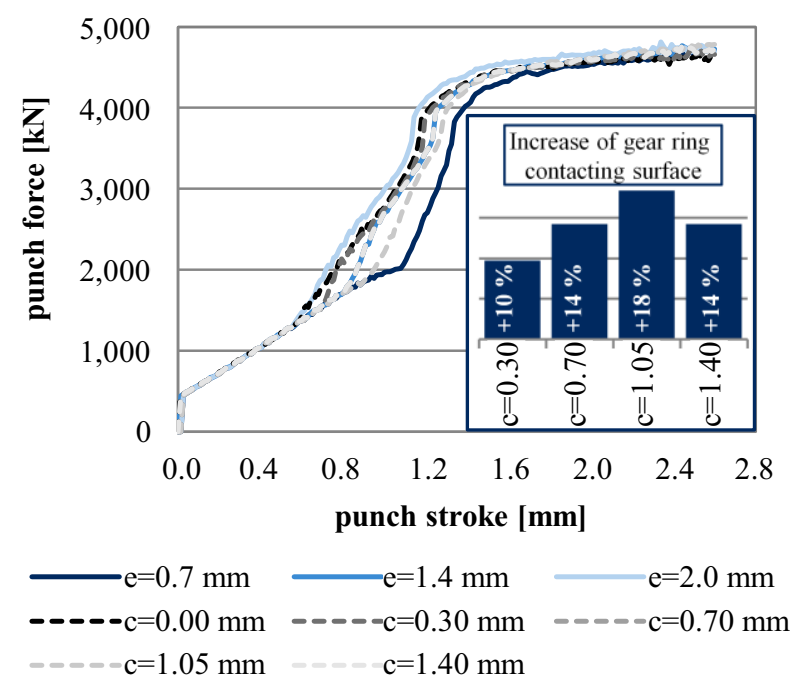

Figure 11: Calculated punch force for different eccentricities and cavity depths of the inner gear ring profile

By increasing eccentricity, the material touches the gear ring at an early stage of the process, which results in a higher punch force at a smaller punch stroke. On the contrary, the maximum punch force level is equal for all eccentricities. Hence, eccentricity has minor effects on punch compression stresses. In comparison to eccentricity, a cavity volume in the inner gear ring affects the punch force even less. However, the bar chart depicted in figure 10 shows the potential benefits of adding a cavity volume to the inner profile of the gear ring. A cavity depth of $\mathrm{c}=0.3 \mathrm{~mm}$ results in an increase of $10 \%$ when contacting the surface of the gearwheel body at the inner gear ring. For a cavity depth of $\mathrm{c}=1.05 \mathrm{~mm}$, a maximum increase of $18 \%$ was determined. A higher shape filling does not automatically result in higher performance of a joint shaft hub assembly [5], but regarding a higher axial form-fit a higher axial force transmission is expected.

\subsubsection{Positioning of upper punch to lower punch and punch to the profile of the gear ring}

Turning the upper punch to the lower punch by half the angle of a punch segment, the spacing of each punch are now directed to a punch segment causing a lower force of the punch segment to extrude the material into the opponent spacing. Hence, the displaced punch segment to punch spacing positioning results in lower punch forces and punch compression stress, as depicted in figure 12 .

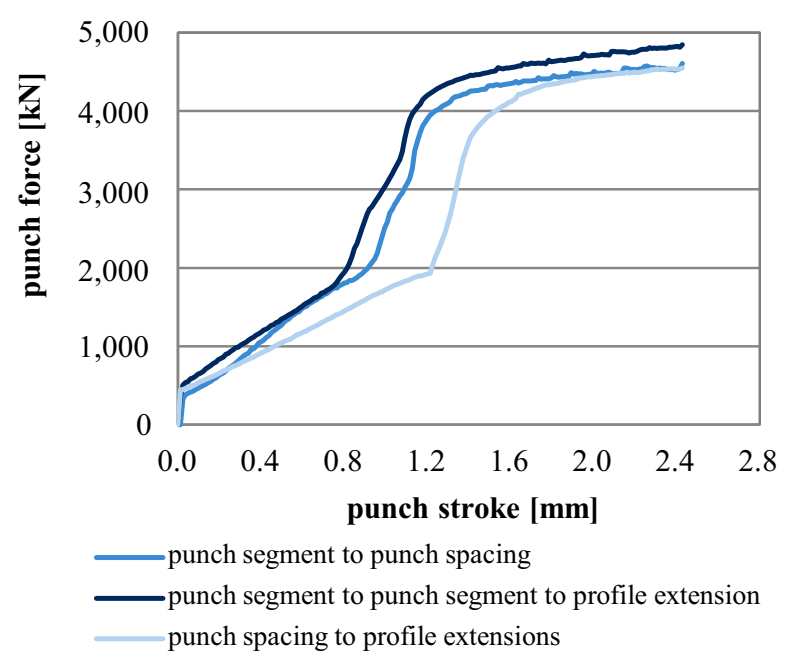

Figure 12: Punch force versus punch stroke curve for different positionings of upper to lower punch and punch to gear ring

Considering a parallel positioning of upper to lower punch, a higher punch force is required, but a symmetric punch assembly also results in a more evenly distributed part height of the gearwheel body. A second investigated positioning evaluated the orientation of gear ring profile extensions to punch segment spacings (gearwheel body wall). Placing the profile extensions to a spacing of punch segment significantly affects both material flow and punch force. The gear ring is touched at a later stage of the process since the distance between punch and gear ring profile extension increased. Despite this, the maximum punch force remains at the same level. However, manufactured gearwheel bodies show better results regarding average part height for a positioning of the punch segment to profile extension of the gear ring.

\subsubsection{Filling of shaft gearing}

Altering the inner punch diameter has minor effects on filling the shaft gearing and on radial stress in the gearwheel body volume, shown in figure 13. A lower distance of punch to shaft seems to result in a straighter axial material flow along the shaft. However, the smallest investigated inner diameter of the punch does not have a higher contacting surface area responsible for transmitting torsion on both the shaft and the gearwheel body. 


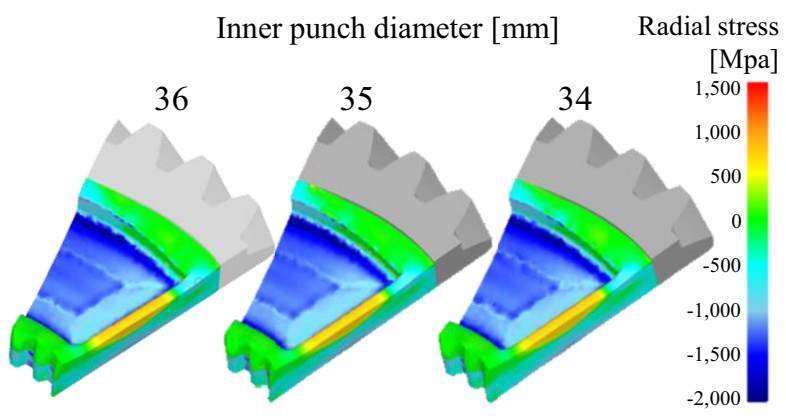

Figure 13: Distribution of radial stress for different inner punch diameters at the end of forging process

\subsection{Investigations on elastic gear ring behaviour}

In figure 14, the elastic behaviour of the gear ring after the forging process and the release of work load are depicted. The gear ring was modelled elastic-plastically to have 80.000 mesh elements. As can be seen, radial compression stress decreases significantly after work load release. Tangential tensile stress on the outside of the gear ring must be evaluated since cracks will occur if the material property limits are exceeded. Despite the release of work load, tangential tensile stress remains at the same level, which is likely to result in cracking.

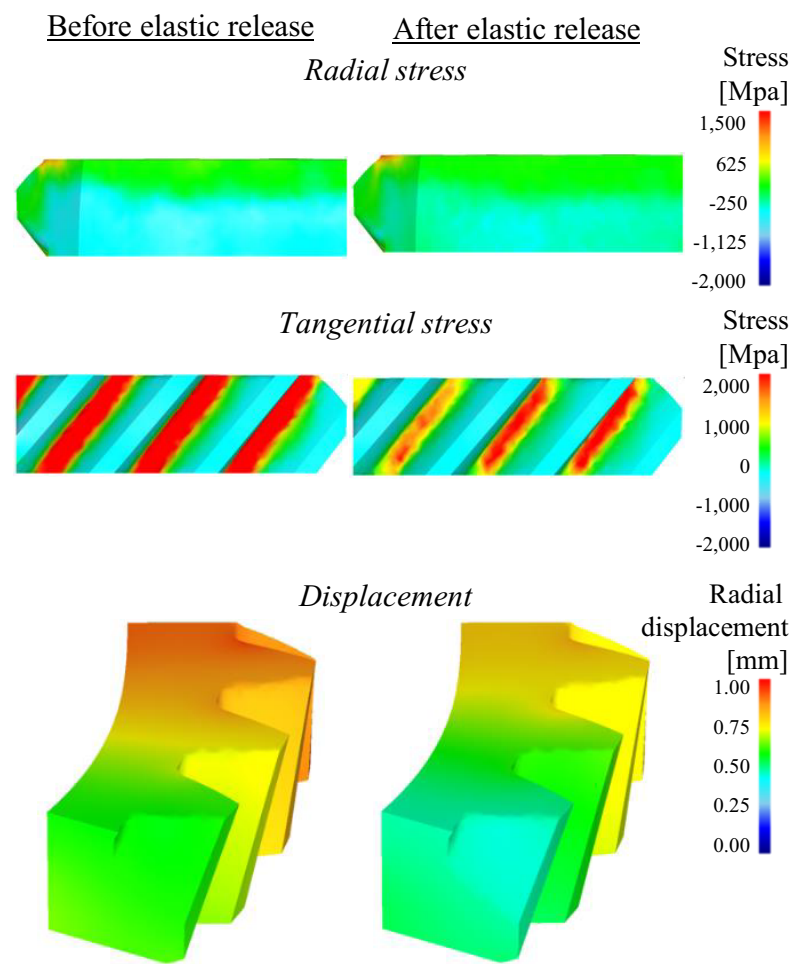

Figure 14: Radial stress, tangential stress and displacement of gear ring after forging process and after work load release for a non-fixed gear ring on the outside

When evaluating gear ring displacement, both inner gear ring profile and gear ring gearing need to be considered in order to result in a non-linear radial deformation. The maximum deformation during the process is up to $0.9 \mathrm{~mm}$. After elastic spring back occurs, a maximum deformation of approx. $0.8 \mathrm{~mm}$ remains in some areas of the gear ring. The contact surface increases by roughly $1 \%$ after work load release.

Assuming an ideal rigid bearing at the outside of the gear ring, the elastic behaviour changes significantly before and after the release of the work load. In figure 15, radial stress, tangential stress, and radial displacement of the gear ring after the forging process and after the release of work load for a fixed gear ring on the outside are depicted. Before the release of work load, radial stress reaches up to higher values. The distribution seems to be quite even on the complete inside, and a higher contact surface can be detected in comparison to a non-fixed gear ring (figure 14).

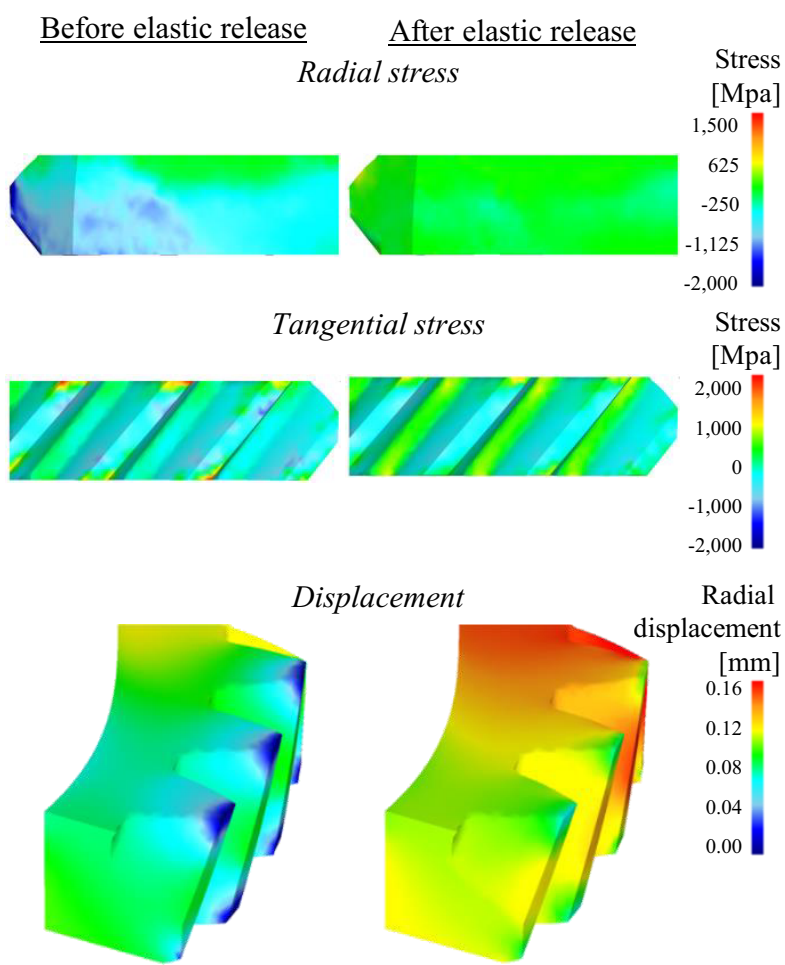

Figure 15: Radial stress, tangential stress and displacement of gear ring after forging process and after work load release for a fixed gear ring on the outside

Furthermore, tangential stress on the outside of the gear ring could be decreased significantly. On the contrary, tangential stress increases after the release of work load, but remains below the values of tangential stress of a non-fixed gear ring. In this case, displacement behaviour is similar to tangential stress. Before releasing the work load, the radial displacement is significantly lower, since the gear ring is fixed at the outside. However, the radial displacement increases after the release of work load. Furthermore, the area of the inner gear ring profile peaks undergoes a larger displacement.

\section{Conclusion}

In this paper, fundamental investigations on material flow, emerging punch forces, and elastic behaviour of a gear ring for joining a built gearwheel body in a multicomponent process were presented. Regarding material 
flow, the blank geometry and the punch positioning showed clear effects on constant part height at the inside and outside. While friction has no considerable influence on the punch force, the wall thickness mostly affects punch forces as well as lightweight potential. The investigations on the inner gear ring profile regarding different eccentricities and cavity depths outline a trend, especially of the performance of built component during usage. The comparison of non-fixed and fixed gear ring bearings show significant differences regarding radial and tangential stresses.

Using a fixed bearing, a bigger decrease of radial stress in the inner gear ring was determined. In contrast, tangential stress and radial displacement were decreased distinctly.

\section{Acknowledgement}

Based on a decision of the German Bundestag, the IGF project $18229 \mathrm{~N}$ of the research associations FOSTA, AWT, FSV, and FVA is supported via the AiF within the program of promoting joint industrial research projects by the Federal Ministry of Economy and Energy.

on the basis of a decision by the German Bundestag

\section{References}

1. M. Hagedorn; K. Weinert, Journal of Materials Processing Technology 153-154 (2004) p. 323-329

2. R. Matsumoto; S. Hanami; A. Ogura; H. Yoshimura; K. Osakada, CIRP Annals - Manufacturing Technology 57, p. 279-282 (2008)

3. F. Dörr, M. Funk, M. Liewald, H. Binz, 11th International Conference on Numerical Methods in Industrial Forming Processes (NUMIFORM 2013), July 6-10, , Shenyang, Liaoning, China (2013)

4. F. Dörr; M. Funk; M. Liewald, H. Binz, In: Neugebauer, R.; Drossel, W.-G. (Hrsg.): $4^{\text {th }}$ International Conference on Accuracy in Forming Technology. Chemnitz, p. 437-450 (2012)

5. F. Dörr; M. Funk; M. Liewald M., H. Binz, In, 11th International Conference on Technology of Plasticity, ICTP 2014, Procedia Engineering 81; Nagoya, Japan, p. 1988-1993 (2014)

6. M. Funk; F. Dörr; H. Binz; M. Liewald, NAFEMS World Congress 2015, 2nd International SPDM Conference, San Diego (2015)

7. J. Wälder; A. Felde; M. Liewald: Hollow lateral extrusion of tubular billets - Further development of the cold forging process Applied Mechanics and Materials, 794, pp 160-165 (2015)
8. J. D. Lawrence: A Catalog of Special Plane Curves. New York: Dover, pp. 168-170 (1972) 